\title{
APRENDIZAGEM ESCOLAR E OS PROJETOS MATEMÁTICOS: CAMINHOS PARA A INOVAÇÃO PEDAGÓGICA
}

\section{ARTIGO ORIGINAL}

VIANA, Suzana Nery ${ }^{1}$

CORREIA, Fernando Luís de Sousa ${ }^{2}$

PEREIRA, José Santos ${ }^{3}$

\begin{abstract}
${ }^{1}$ Mestranda em Ciências da Educação - Inovação Pedagógica - na Universidade da Madeira - Funchal - Portugal, Pós - Graduada em Programação do Ensino de
\end{abstract} Matemática (2005) pela Universidade de Pernambuco - UPE, Bacharel em Engenharia de Pesca (2006) pela Universidade do Estado da Bahia- UNEB, Licenciada em Ciências com habilitação em Matemática (2002) pela Autarquia de Ensino Superior de Arcoverde-AESA/Centro de Ensino Superior de Arcoverde-CESA. 2 Doutor em Ciências da Educação - Inovação Pedagógica (2011) pela Universidade da Madeira - Funchal - Portugal; Mestre em Ciências da Educação - Supervisão Pedagógica (2004) pela Universidade da Madeira - Funchal - Portugal; Diploma de Estudos Superiores Especializados - Curso de Estudos Superiores Especializados em Educação Especial - Educação Pré-Escolar e Ensino Básico (1 Ciclo), na área de especialização de Problemas Motores Profundos (1998) pela Escola Superior de Educação de Lisboa - Lisboa - Portugal; Curso de Especialização - Curso de Formação de Professores do Ensino Especial com incidência em Deficiência Motora (1986) pelo Instituto António Aurélio da Costa Ferreira - Lisboa - Portugal; Bacharelato - Curso do Magistério Primário (1979) pela Escola do Magistério Primário do Funchal - Funchal - Portugal.

${ }^{3}$ Doutor em Ciências da Educação - Inovação Pedagógica (2013) pela Universidade da Madeira - UMa, em Funchal-Portugal; Mestre em Teologia (2002) pela Faculdade de Teologia e Ciências Sociais do Recife - FATER, em Recife-PE, Pósgraduação/Especiação em Currículo Escolar e Praticas Pedagógicas (1999) pela 
VIANA, Suzana Nery. CORREIA, Fernando Luís de Sousa. PEREIRA, José Santos. Aprendizagem Escolar e os Projetos Matemáticos: caminhos para a Inovação Pedagógica. Revista Científica Multidisciplinar Núcleo do Conhecimento. Ano 05, Ed. 12, Vol. 18, pp. 101-115. Dezembro de 2020. ISSN: 2448-0959, Link de acesso: https://www.nucleodoconhecimento.com.br/educacao/projetos-matematicos

\section{RESUMO}

O objetivo deste artigo é discutir a importância do trabalho com projetos na disciplina de matemática na perspectiva da inovação pedagógica. Para tal, parte-se de uma revisão bibliográfica, e tem-se como objetivo, analisar as contribuições dos projetos escolares na aprendizagem matemática. A metodologia baseada em projetos permite ao estudante o desenvolvimento da criticidade e da reflexão, e como consequência a elevação da autoestima e a melhoria da aprendizagem. Dessa forma, a relevância do presente estudo, irá contribuir para que os professores de todas as áreas do currículo escolar, construam suas práticas, valorizando a elaboração de projetos, mediados pela construção coletiva. Após a leitura minuciosa de cada obra utilizada nesse trabalho, chega-se à conclusão de que os projetos matemáticos, permitem a ocorrência de inovação pedagógica dentro do ambiente escolar, levando os estudantes a tornarem-se protagonistas de seu próprio conhecimento.

Palavras-chave: Aprendizagem matemática, inovação pedagógica, projetos.

\section{INTRODUÇÃO}

A atual sociedade vem passando por rápidas mudanças, e na educação essas transformações são visíveis, principalmente no que diz respeito a quebra de paradigmas, levando os professores a utilizarem novas metodologias e a construção

Fundação de Ensino Superior de Olinda - FUNESO, em Olinda-PE; Graduado em Pedagogia (1987) pela Fundação de Ensino Superior de Olinda, em Olinda-PE e Graduado em Crédito e Finanças (1982) pela Universidade Federal de Pernambuco - UFPE, em Recife-PE. 
de novos conceitos, objetivando um melhor desempenho das aprendizagens, principalmente em matemática, disciplina essa que embora muitos estudantes não gostem, ela é considerada como uma área do conhecimento muito importante para toda as ciências, e portanto, requer do professor um fazer diferenciado, deixando de lado velhas práticas que não contribuem para as mudanças que vêm ocorrendo no campo educacional e na sociedade como um todo.

De acordo Behrens (2011), "pensar na Educação implica refletir sobre os paradigmas que caracterizaram o século XX e a projeção das mudanças paradigmáticas no início do século XXl" (BEHRENS, 2011, p. 17). Essas mudanças exigem da escola, trabalhar com projetos que permitam ao estudante, assumir o papel de protagonista, no qual ele mesmo traça seus próprios projetos de vida, suas concepções, rumo às suas realizações. Dessa maneira, o estudante torna-se coautor na construção intelectual de sua história, principalmente na aprendizagem matemática. Tudo isso provoca mudanças, contribuindo para que ocorra, a inovação pedagógica. Em relação às mudanças educacionais, Moran, et al (2000, p.17-18), afirma que:

As mudanças na educação dependem também dos alunos. Alunos curiosos e motivados facilitam enormemente o processo, estimulam as melhores qualidades do professor, tornam-se interlocutores lúcidos e parceiros de caminhada do professor-educador. Alunos motivados aprendem e ensinam, avançam mais, ajudam o professor a ajudá-los melhor.

Dentro desse entendimento, é possível afirmar que tanto o professor como os estudantes são responsáveis pelo êxito no fazer pedagógico, porque não há mais espaço dentro da escola para que os professores habilitem pessoas como mão-deobra para os empregos instáveis industriais, como acontecia no período de auge do paradigma fabril (DELORS, 1999).

No atual contexto social, a escola tem como papel fundamental formar indivíduos capazes de evoluir, de dominarem as rápidas transformações as quais vêm sendo observadas no contexto social e a adaptarem-se a esse mundo permeado por tecnologias. 
Nesse contexto, pode-se afirmar que a educação lida com o futuro, e para tanto, já não se concebe mais um ensino baseado unicamente em recursos arcaicos como por exemplo: quadro, giz e cadernos e livros, mas precisa oferecer métodos que possibilitem aos estudantes, criarem estratégias para obterem o conhecimento, como é o caso do trabalho com projetos.

O ensino baseado em projetos, permite ao estudante, a aquisição de conhecimentos e habilidades, levando-o a investigar e responder a um desafio, um problema ou uma questão complexa (ROSA, 2015).

Nesse entendimento, esse artigo parte de uma revisão bibliográfica que se baseia no estudo sobre o ensino de matemática e a importância dos projetos escolares, na perspectiva de que ocorra nesse processo, a inovação pedagógica, tendo como objetivo analisar as contribuições dos projetos escolares na aprendizagem matemática. Para responder ao objetivo elencado, colocou-se esta questão problema: os projetos matemáticos desenvolvidos na escola contribuem para a inovação pedagógica? Essa reflexão nos ajuda a perceber a importância do professor utilizar metodologias que proporcionem ao estudante descobrir novas formas de aprender. Esse estudo se justifica por entender-se que a inovação pedagógica dar-se-á na relação entre o que se ensina e como se aprende e na metodologia empregada na sala de aula. Assim, esse estudo tem enfoque qualitativo de natureza etnográfica, cujo foco é o estudo do comportamento e a cultura dos grupos (professor e estudante).

\section{INOVAÇÃO PEDAGÓGICA: O QUE DIZEM OS AUTORES}

O debate a respeito do tema inovação, nos conduz a compreensão de seu significado dentro do contexto pedagógico. Segundo Fino (2011), para: "[...] encontrar inovação pedagógica necessita de um persistente trabalho de garimpeiro, cuja atividade se caracteriza muito mais por procurar do que pela felicidade de encontrar" (FINO, 2011, p. 111). Apesar de entender que encontrar a inovação pedagógica na maioria das escolas, não é uma prática rotineira, Fino (2011), não descarta a possibilidade de encontrá-la dentro da sala de aula, a depender de como se mostrem as práticas pedagógicas vivenciadas pelos seus atores (estudantes e professor). 
Corroborando com o autor, Messina (2001, p.225), complementa ao citar que: "podese dizer que a inovação é antes um processo, não apenas conhecimento". Diante dessa afirmação, pode-se compreender que inovar é, antes de tudo, provocar mudanças de maneira planejada na busca de se obter melhorias. Correia (2011, p. 42) afirma que:

A inovação é um fenómeno de "destruição criativa". Ela ocorre dentro da história, evolui junto com ela e transforma-a constantemente. A inovação não tem idade, nem lugar, nem tempo. $\mathrm{Na}$ aldeia global da cultura tecnológica, a inovação já não é uma escolha, mas uma constante da vida. Rejeitá-la só pode resultar na exclusão da moderna comunidade internacional.

A inovação pedagógica, abrolha como um reflexo do rompimento de paradigmas que perpetuam nas práticas pedagógicas tradicionais, que não têm contribuído para um ensino satisfatório. "A inovação é, em primeiro lugar, uma condição do espírito, em vez de um estado de espírito" (CORREIA, 2011, p. 42). Assim, práticas pedagógicas inovadoras "implicam mudanças qualitativas nas práticas pedagógicas e essas mudanças envolvem sempre um posicionamento crítico, explícito ou implícito, face às práticas pedagógicas tradicionais" (FINO, 2008, p. 10). Aprofundando a argumentação, Pereira (2011, p. 275) traz, no tocante à inovação pedagógica, que "a inovação só se efetiva nos liames da prática pedagógica do professor inserida num determinado contexto histórico", dessa forma deve-se reconhecer que esse contexto requer uma relação clara entre a vida pragmática e a vida real. Nesse incurso, a "inovação talvez seja mais provável em ambientes de aprendizagem menos marcados histórica e culturalmente pelo velho paradigma" (FINO, 2011, p. 111). Assim, a inovação não é, nem acontece, somente num fator isolado modificado em uma prática; para que ela ocorra, se faz necessário que haja a ruptura de antigas práticas, para a busca por novas culturas escolares. A cultura "pode ser definida como formas materiais e espirituais, com que os indivíduos de um grupo convivem, nas quais atuam e se comunicam" (OSTROWER, 2010, p. 13). Sendo assim, a cultura escolar reflete as práticas pedagógicas que os envolvidos nesse processo proferem. Nessa perspectiva, buscar novas culturas escolares significa antes de tudo, repensar essas práticas de maneira que elas possam abarcar as novas demandas socioculturais 
deste século, levando em consideração que "as escolas e as turmas também podem ser pensadas como culturas a serem estudadas" (FINO e SOUSA, 2011, p. 60). Na modernidade é de suma importância a escola, propor o desenvolvimento de projetos que propiciem trocas interativas, fazendo emergir um paradigma coletivo, que atenda às demandas dos indivíduos, principalmente na sociedade marcada pelo capitalismo e por uma crescente desigualdade social. A palavra modernidade de acordo com Touraine (1996, p.4),

A ideia de modernidade, na sua forma mais ambiciosa, foi a afirmação de que o homem é o que ele faz, e que, portanto, deve existir uma correspondência cada vez mais estreita entre produção, tornada mais eficaz pela ciência, a tecnologia ou a administração, a organização da sociedade, regulada pela lei e a vida pessoal, animada pelo interesse, mas também pela vontade de se liberar de todas as opressões. (...) É a razão que anima a ciência e suas aplicações; é ela também que comanda a adaptação da vida social às necessidades individuais ou coletivas; é ela, finalmente, que substitui a arbitrariedade e a violência pelo Estado de direito e pelo mercado. "A humanidade, agindo segundo suas leis, avança simultaneamente em direção à abundância, à liberdade e à felicidade"

Dentro desse entendimento, no atual cenário social, requer que as práticas pedagógicas, se adequem à modernidade, fenômeno esse, que traz em seu bojo, a relevância de uma aprendizagem que leve o estudante a pesquisar, a discutir, a rever e reformular conceitos. Inovação é um termo empregado com bastante frequência; porém, a sua definição ainda não é apresentada como consensual.

Correia (2011, p. 56) diz-nos que:

Se numa perspectiva mais radical se entende Inovação como ruptura paradigmática, existe uma perspectiva mais generalizada que vê a Inovação como a aplicação de um novo recurso ou de uma abordagem que promove mudança de práticas sociais, que se consideram importantes. No campo da educação, esta pode ser a aplicação de uma nova abordagem ou questionamento, o uso de uma nova ferramenta digital ou uma nova organização do espaço - que traz algum valor, alterando a prática social do ensino e da aprendizagem.

Nesse contexto, o trabalho com projetos apresenta-se por demais relevante no processo ensino aprendizagem, como será abordado a seguir. 


\section{A IMPORTÂNCIA DOTRABALHO COM PROJETOS}

$\mathrm{Na}$ escola o trabalho com projetos não é uma novidade, contudo na disciplina de matemática ainda não é plenamente utilizado pelo professor. Esse fato pode se dar pela concepção que muitos professores possuem, de que trabalhar com projetos é complexo e que os estudantes não gostam, contudo, isso não é verdade. As atividades propostas no desenvolvimento de projetos leva o estudante a se tornar um ser autônomo, reflexivo e crítico.

Trabalhar com projetos possibilita a interação de todos para a construção coletiva do aprendizado. Nesse tipo de atividade, o foco é a melhoria da educação, a qual se desenvolve na contínua observação pelo professor em relação ao estudante, principalmente na forma como esses aprendem. Na perspectiva de Morin (2000), trabalhar com projetos colabora para que o estudante interiorize o conhecimento, contribuindo para promover melhorias à qualidade do ensino. Nesse sentido, na aprendizagem baseada em projeto, o estudante é estimulado a desenvolver uma nova postura, em que o conhecimento apreendido se dá de forma individual e ao mesmo tempo coletiva, no qual um ajuda o outro, quer seja, contribuindo com o acréscimo de conceitos, quer seja, refletindo juntos, exigindo a articulação de todos os conhecimentos disciplinares trabalhados ao longo da formação de forma integrada, mediada pelo professor.

De acordo com Pinto et al (2013), trabalhar com projetos requer ações que não priorizem a repetição de conteúdos memorizados, mas que envolvam o planejamento de metas, perpassando todo o processo até a sua avaliação. Na utilização de projetos, o professor se desfaz da posição de um mero transmissor e passa a assumir, conforme Fino (2008, p. 2), "um papel mais periférico, servindo de assistente, recurso, guia, agente metacognitivo", caracterizando como um professor que inova suas práticas. Essa prática se contrapõe ao ato de ensinar, que é visto como meramente técnico, no qual o professor apenas desenvolve o currículo de acordo com pressupostos didáticos previamente estabelecidos. 
Em relação aos estudantes, eles desenvolvem os projetos orientados pelo professor em seu processo de aprendizagem por meio de estímulos, diálogos, incentivos que os levam a experiência de aprendizagem. Dessa maneira, ao longo do processo, os estudantes tomam decisões que envolvem o desenvolvimento da ideia do projeto, bem como a decisão do escopo do projeto, a seleção dos padrões, ainda a incorporação dos resultados simulados, como também do desenvolvimento a partir da formulação do projeto e criação do melhor ambiente de trabalho (MARKHAM; LARMER; RAVITZ, 2008).

Diante do exposto, é preciso entender que, embora a educação ainda se movimente a passos muito lentos em relação ao desenvolvimento de projetos na disciplina de matemática, é incontestável a rica contribuição que esses têm, para uma aprendizagem mais ativa e eficaz, tendo em vista que o trabalho coletivo é essencial na aquisição, construção e compartilhamento do conhecimento.

\section{O ENSINO DE MATEMÁTICA NO CONTEXTO ESCOLAR}

Muitos estudantes têm o direito de conviver em um ambiente escolar criativo e ao mesmo tempo enriquecedor. Para tanto, se faz necessário entender que a prática pedagógica precisa estar focada em uma aprendizagem prazerosa e dinâmica, na qual o diálogo deve ser o foco dessa ação. Dessa forma o professor, e em especial o de matemática, deve ser capaz de fazer os estudantes interagirem com os diferentes conteúdos dessa disciplina, articulando-os com atividades e experiências por meio do trabalho em equipe fortalecendo, além dos laços de amizade, a possibilidade de contribuir para a quebra do "temor" quando se fala em matemática. Esse fato é observado quando se escuta de muitos professores, que os estudantes tem mal desempenho em todas as turmas e anos, seja do ensino fundamental ao ensino médio, diagnosticado por meio das avaliações que os estudantes realizam. Esse panorama tem colocado o Brasil, em um patamar muito inferior em relação aos outros países, em termo de aprendizagens dos estudantes. Esse cenário pode estar atrelado à falta de habilidade do professor em mediar os conteúdos. 
É comum que grande parte dos professores, ao ensinarem os conteúdos de matemática não atentem para contextualizá-los, para explicarem suas funções, bem como em que contexto se utiliza, para que esses conteúdos servem, assim como a sua importância social. Agindo assim, o ensino de matemática, quando desprovido de seus significados e sua importância, acaba acarretando uma gama de dificuldades no aprendizado dos estudantes, que perduram durante todo o processo escolar. Nesse viés, Soares $(2011$, p. 5), afirma que:

A Matemática escolar, muitas vezes, se distância da Matemática da vida, ou seja, a Matemática que aprendemos na escola parece não ser a utilizada nas nossas relações, enquanto membros de uma sociedade, na qual a cada dia se faz necessário o domínio de tecnologias ligadas à Matemática.

A afirmação de Soares (2011), pode estar relacionada à explicação que vem sendo mostrada nas avaliações externas e internas às quais os estudantes são submetidos, a baixa aprendizagem dos estudantes em matemática, caracterizando essa disciplina que não consegue preparar os estudantes com as competências necessárias que esse ensino requer. De acordo com os Parâmetros Curriculares Nacionais (PCNs), o trabalho com base na contextualização matemática é importante para que essa disciplina :

[...] desempenhe, equilibrada e indissociavelmente, seu papel na formação de capacidades intelectuais, na estruturação do pensamento, na agilização do raciocínio dedutivo do aluno, na sua aplicação a problemas, situações da vida cotidiana e atividades do mundo do trabalho e no apoio à construção de conhecimentos em outras áreas curriculares (BRASIL, 1997, p 21).

Nesse ínterim, interessa destacar que a falta de habilidade do professor de matemática em saber contextualizar os conteúdos em sala de aula, contribui fortemente para que os estudantes passem a não gostar dessa disciplina. Essa mesma concepção possui, Andrade; Viégas e Tristão (2009, p.4), quando realçam que:

[...] Percebe-se que os alunos, mesmo os plenamente alfabetizados na linguagem corrente, não possuem as habilidades básicas para o entendimento da Matemática. Não conseguem, muitas vezes, concluir 
com exatidão as quatro operações fundamentais: adição, subtração, multiplicação e divisão. Tampouco conseguem interpretá-la nas situações-problema, em que o seu ensino está hoje embasado. Quando não consegue atribuir um sentido prático à Matemática, o aluno passa a ter aversão por ela, o que contribui para o consumado quadro de "analfabetismo" instaurado na contemporaneidade.

Para os autores, os estudantes ainda que tenham o domínio da leitura e da escrita, não conseguem resolver e nem interpretar problemas básicos matemáticos, passando a ser um grande desafio para o ensino, mas, que de forma urgente, precisa ser vencido pelo professor por meio de políticas de formação e da troca de experiências entre professores mais experientes e da renovação de suas práticas.

A dificuldade de alguns professores para lecionarem com essa disciplina, devido à concepção que eles possuem em relação a própria matemática, bem como o receio de trabalhar com novas metodologias, como quebrar paradigmas, têm sido uma constante no ambiente escolar. Diante desse contento de mudança paradigmática, Toffler (1973), diz que o processo adaptativo às mudanças, além de ser difícil, gera também consequências desnorteadoras, tais consequências podem levar a uma desorganização no processo educativo. Freire (2002), colabora, ao compactuar com a ideia de que mudar é difícil, contudo, possível de acontecer, daí a relevância da construção do conhecimento de forma coletiva, para a transformação gerada pelo ser humano, rumo a uma aprendizagem igualitária. Tal entendimento, leva-se à compreensão de que a sociedade pós-moderna opera frente ao paradigma moderno, centrado na globalização e no emergente avanço tecnológico.

\section{METODOLOGIA}

Considerando a relevância desse estudo, optou-se por uma pesquisa qualitativa, de natureza etnográfica e teve-se como instrumento, o estudo bibliográfico de vários teóricos que abordam sobre o tema. $O$ enfoque etnográfico, comumente empregado nesse estudo, foi conjugado à pesquisa qualitativa, pois ela tem como foco principal, descrever, entender e explicar os fenômenos socias dos grupos estudados. Nesse contexto, esse tipo de pesquisa e enfoque tornou-se imprescindível para compreender os aspectos referentes à área educacional e, dessa forma, contribuir 
para a percepção da realidade por meio de representações e significações que os sujeitos sociais atribuem, quando envolvidos em ações pedagógicas no contexto escolar.

$\mathrm{Na}$ pesquisa bibliográfica as temáticas discutidas vêm contribuir para um ensino voltado ao desenvolvimento de projetos matemáticos que visam colaborar para a construção da autonomia do estudante, proporcionando um aprendizado coletivo.

\section{RESULTADOS E DISCUSSÃO}

É comum encontramos uma grande parcela de professores seguindo uma proposta cujo centro encontra-se na pedagogia dos conteúdos, com atividades tradicionais e rotineiras sem valorizar as vozes e a individualidade de cada estudante. Por outro lado, ainda é possível observar, (apesar de em número reduzido), que também há escolas que valorizam essas vozes, culminando para a cultura juvenil, alicerçada na pedagogia de projetos, que oportuniza ao estudante assumir a posição de protagonista, descobridor de novos conceitos, reformulando outros saberes. Para Meira (2016, p.71):

O novo ou a novidade emergem continuamente no curso de nossas vidas, como algo não familiar e sobre o qual não temos estratégias bem definidas com as quais realizar escolhas ou tomar decisões. Deparamonos diariamente com pequenas novidades, às vezes grandes, menos ou mais prováveis. O cotidiano nunca é exatamente o mesmo e estamos num contínuo fluxo de mudança. Esse fenômeno não nos é prontamente evidente, pois criamos algo como uma "ilusão de mesmice", a fim de não sermos paralisados por nossa crescente inabilidade em lidarmos com o desconhecido. Assim, sempre "assimilaremos" (em modo subconsciente, por assim dizer) o novo às coisas que já nos eram familiares. Mas isso não é sempre assim. Algumas vezes seremos de tal forma impactados por um evento ou coisa que nossa conduta será significativamente transformada para lidar com a singularidade deste cenário emergente.

Corroborando com o autor, para acontecer o "novo", o "velho" precisa ser percebido como algo que já não consegue atender à demanda atual da sociedade, às expectativas dos estudantes. É preciso arriscar-se, mergulhar em um outro olhar, provocar e mediar o trabalho coletivo. Dessa maneira, o trabalho com projetos na 
escola favorece uma prática significativa, na qual os sujeitos aprendentes experimentam uma proposta revolucionária, um novo momento de aprendizagem, e ao mesmo tempo a necessidade urgente de quebrar barreiras. Além disso, os Parâmetros Curriculares Nacionais - PCNs (BRASIL, 1997), documento muito importante que norteiam as práticas pedagógicas, vem contribuir ao descrever que a aprendizagem Matemática deve contribuir também para o desenvolvimento do raciocínio lógico, da coerência, o que vai além dos aspectos práticos. Tudo isso demanda, um novo olhar para o papel do professor dentro do seu fazer pedagógico, que se entrelaça como desafio, que poderá ser vencido dependendo da visão que o professor possui em enxergar o novo cenário educacional que vem se estabelecendo, "desafio este que deve ser enfrentado pelo professor, bem como o de refletir e repensar sua prática pedagógica" (SILVA; PRATES e RIBEIRO, 2016, p. 106). A mudança e postura crítica frente ao novo cenário, direciona a inovação dentro do ambiente escolar.

A inovação pedagógica para a aprendizagem de Matemática se reflete em ações que são desenvolvidas na sala de aula, nas quais os estudantes deixam de ser, um ser inerte e passivo e passam a ser o construtor ativo de seus próprios conhecimentos.

A partir desse entendimento, é importante salientar que a inovação parte da ruptura de natureza cultural de métodos de ensino utilizados de modo tradicional, proporcionando a abertura de novos ambientes com novas culturas de trabalho que estejam aliadas às práticas de ensino, alterando como prioridade o currículo programático. Portanto, como afirma Fino (2008, p.2), "[...] o caminho da inovação raramente passa pelo consenso ou pelo senso comum, mas por saltos premeditados e absolutamente assumidos em direcção ao muitas vezes inesperado. Aliás, se a inovação não fosse heterodoxa, não era inovação". Sendo assim, para que a inovação seja um processo que ocorra na sala de aula, é preciso, como o próprio termo citado por Fino (2008), "heterodoxa”, que significa, oposição, contestação, que o professor se contraponha a determinados métodos que não favorecem a um bom aprendizado, passando a melhorar, a inovar sua própria didática. É oportuno aqui salientar que as práticas pedagógicas bem sucedidas, principalmente em matemática, envolvem não 
somente o professor, mas o estudante e toda a escola para darem sustentação e colaboração nas metodologias que apoiam esse novo fazer. Assim, todos os envolvidos se complementam e se ajudam.

É importante frisar que a matemática é um componente indispensável à formação de todo estudante, e dessa forma, na formação do professor dessa disciplina, deve-se sinalizar a necessidade de associar seu preparo acadêmico com o aprimoramento das práticas educativas. Isso porque, o conhecimento de processos de investigação de seu fazer, possibilitará o aperfeiçoamento das suas ações pedagógicas, que devem ser desenvolvidas com ênfase nos procedimentos de observação, da reflexão e da avaliação contínua, visando à atuação em situações contextualizadas. A esse respeito, Ponte e Chapman (2007, p. 103), afirmam que para "torna-se efetivamente professor não é suficiente desenvolver somente o conhecimento matemático, embora seja essencial, também é preciso desenvolver o conhecimento sobre o ensino de matemática". Seguindo esse entendimento, em relação ao citado pelos autores, torna-se explicito que eles fazem referência à disciplina de Matemática como um campo formalizado do pensamento humano e ao mesmo tempo se referem à esfera do conhecimento profissional, esse último vai depender das condições sociais, dos recursos disponibilizados principalmente os tecnológicos, dos valores educacionais aos quais a escola se propõe e da mesma importância, às propostas curriculares. Nesse incurso, o currículo não se restringe apenas à programação de objetivos, metodologias, conteúdos e recomendações para avaliação posterior, como nas demais disciplinas da grade escolar, mas vai muito além, e abrange de forma igual um plano de propostas investigativas, de resolução de problemas, com foco na realidade social, o desenvolvimento de projetos e sem deixar de lado, o uso de tecnologias, envolvendo seus atores, em um processo de aprendizagem a partir do levantamento de conjecturas, levando-os a tirarem suas próprias conclusões. Fica dessa forma evidenciado, que o ensino de matemática pautado em projetos pedagógicos mobiliza, não somente uma turma especifica, mas toda a escola, desde o planejamento até a concretização de resultados. Este fazer, impacta a educação e a escola de diferentes formas e perspectivas, a de repensar e se reestruturar para reelaborar seus projetos formativos, visando atender as exigências da emergente 
sociedade que vem se delineando. Agindo assim, a escola passa a ser vista como um espaço em que todos querem estar participando, criando, fazendo e refazendo, num ambiente que estimula, torce, planeja e respeita as adversidades.

Os projetos por serem pedagógicos, se alicerçam em uma gama de recursos entre eles: jogos, problemas matemáticos, modelagem, gincana, dentre outros. Tudo isso parte de uma nova forma de conceber a matemática como um ensino móvel, mediante o trabalho com projetos.

\section{CONSIDERAÇÕES FINAIS}

O conceito de Inovação pedagógica, concebido pelos autores nesse artigo, nos leva a compreensão de que ela é, principalmente, um processo de mudança; um novo jeito de fazer diferente, pautado nos anseios que o contexto social e escolar impõe. Nessa trajetória, entendemos que o ensino que tem como meta, trabalhar com projetos, consolida uma aprendizagem significativa, em um processo dinâmico, de criação e reflexão, no qual novos conhecimentos são gerados e modificados de forma sistemática.

Os projetos pedagógicos conduzem os estudantes ao protagonismo juvenil, cujo fato se observa quando os estudantes expõem tudo aquilo que aprenderam de forma segura em qualquer contexto, sendo capaz de criarem novos significados do que fora estudado.

Diante dos resultados discutidos nesse estudo, é possível inferir, que estudar o ensino de matemática e a importância de uma prática pedagógica nos moldes de projetos, permitiu-nos utilizar uma lente de aumento, que pode nos aproximar ou afastar do solo carregado de dados, que pode romper com um paradigma totalmente tradicional, rumo a uma prática pedagógica completamente inovadora.

\section{REFERÊNCIAS}

ANDRADE, S. R.; VIÉGAS, R. F.; TRISTÃO, A. M. Políticas de avaliação do ensino básico: A educação matemática no Brasil. Pesquisa em Debate, Ed. Especial. 
2009.

Disponível

em:

http://

ww.pesquisaemdebate.net/docs/pesquisaEmDebate10.pdf>. Acesso em:13 de dez. 2020.

BEHRENS, M. A. O paradigma emergente e a prática pedagógica. 5. ed. Petrópolis, Rio de Janeiro: Vozes, 2011.

BRASIL. Parâmetros Curriculares Nacionais: Matemática, Secretaria de Educação Fundamental, Brasília: MEC/SEF, 1997.

CORREIA, F.; Internet - sala de estudo virtual. 2011. 445 f. Tese (Doutoramento em Ciências da Educação na área de Inovação Pedagógica). Universidade da Madeira. Funchal, 2011.

DELORS, J. (org.). Educação. In: Relatório para UNESCO da Comissão Internacional sobre Educação para o Século XXI. 3. Ed. São Paulo: Editora Cortez, 1999.

FINO,C.N.; A etnografia enquanto método: um modo de entender as culturas (escolares) locais. In: ESCALLIER, C.; VERÍSSIMO, N. (org.). Educação e Cultura. Funchal: DCE - Universidade da Madeira, 2008, p. 43-53.

Inovação Pedagógica, Etnografia, Distanciação. In: FINO, C. N. (org). Etnografia da Educação. Funchal: Universidade da Madeira. CIE - UMa, 2011, p. 95-117.

FREIRE, P. Ação cultural para a liberdade. São Paulo: Paz e Terra, 2002.

MARKHAM, T.; LARMER, J.; RAVITZ, J. Aprendizagem baseada em projetos: guia para professores de ensino fundamental e médio. Porto Alegre: Artmed, 2008.

MEIRA, L. Inovação e pedagogias inovadoras para hackear a escola. Pesquisa sobre o uso das tecnologias da informação e comunicação nas escolas brasileiras. Comitê gestor da internet no Brasil, São Paulo: 2016. Disponível: em www.cetic.br. Acesso em 10 de dez. de 2020. 
MESSINA, G. Mudança e Inovação Educacional. Notas para Reflexão. Cadernos de Pesquisa, n. 114, p. 225-133, nov., 2001.

MORAN, J. M. et al. Novas tecnologias e mediação pedagógica. 6. ed. Campinas: Papirus, 2000.

MORIN, E. Os 7 saberes necessários à educação do futuro. São Paulo: Cortez. 2000.

OSTROWER, F.; Criatividade e processo de criação. Petrópolis: Vozes, 2010.

PEREIRA, J. S.; Ensino médio e cultura juvenil: um olhar etnográfico sobre a aula, como espaço desconstrução do conhecimento de alunos e alunas. 2011. 301 f. Tese (Doutoramento em Ciências da Educação na área de Inovação Pedagógica). Universidade da Madeira. Funchal, 2011.

PINTO, A. S. da S. Org. (2013).O Laboratório de Metodologias Inovadoras e sua pesquisa sobre o uso de metodologias ativas pelos cursos de licenciatura do UNISAL, Lorena - estendendo o conhecimento para além da sala de aula. Revista Ciências da Educação, ano XV, v. 2, n. 29, p.67-79, dez. Disponível em: $<$ http://www.revista.unisal.br/ojs/index.php/educacao/article/view/288>. Acesso em: 20 dez. 2020.

PONTE, J. P., CHAPMAN, O. Preservise Mathematics Teachers'Knowledge and Development. [s.1]. Preprint, 2007.

ROSA J.; L C.; Metodologias Ativas de Aprendizagem para a Educação a distância: uma análise didática para dinamizar sua aplicabilidade.100 f. Dissertação (Mestrado em Tecnologias da Inteligência e Design Digital) - Pontifícia Universidade Católica de São Paulo, São Paulo, 2015. Disponível em: https://sapientia.pucsp.br/handle/handle/18201. Acesso em: 16 dez. 2020. 
SILVA, I. de C. S; PRATES, T. da S; RIBEIRO, L. F. S. As Novas Tecnologias e aprendizagem: desafios enfrentados pelo professor na sala de aula. Revista Em Debate (UFSC), Florianópolis, volume 16, p. 107-123, 2016. ISSN 1980-3532

SOARES, F. G. E. P. As atitudes de alunos do Ensino Básico em relação à Matemática e o papel do professor. Campo Grande.2011.

SOUSA, J. M. Currículo e etnografia da educação. In: Fino, C. N. Etnografia da Educação. Funchal: Universidade da Madeira. CIE-Uma, 2011, p. 45-68.

TOFFLER, A. Choque do futuro. Lisboa: Livros do Brasil, 1970.

TOURAINE, A. Iguais e Diferentes: poderemos viver juntos. Coleção Epistemologia e Sociedade. Lisboa: Editora Piaget, 1996.

Enviado: Dezembro, 2020.

Aprovado: Dezembro, 2020. 